\title{
$17 \beta$-estradiol-induced growth of triple-negative breast cancer cells is prevented by the reduction of GPER expression after treatment with gefitinib
}

\author{
RAINER GIRGERT, GÜNTER EMONS and CARSTEN GRÜNDKER
}

Department of Gynecology and Obstetrics, School of Medicine, University of Göttingen, D-37075 Göttingen, Germany

Received June 30, 2016; Accepted September 1, 2016

DOI: $10.3892 /$ or.2016.5306

\begin{abstract}
Triple-negative breast cancers (TNBCs) are neither susceptible to endocrine therapy due to a lack of estrogen receptor $\alpha$ expression nor trastuzumab. TNBCs frequently overexpress epidermal growth factor receptor (EGFR) and membrane bound estrogen receptor, GPER. To a certain extent the growth of TNBCs is stimulated by $17 \beta$-estradiol via GPER. We analyzed whether inhibition of EGFR by gefitinib reduces the expression of GPER and subsequent signal transduction in TNBC cells. Dependence of proliferation on $17 \beta$-estradiol was determined using Alamar Blue assay. Expression of GPR30 and activation of c-src, EGFR and cAMP-responsive element binding (CREB) protein by $17 \beta$-estradiol was analyzed by western blotting. Expression of c-fos, cyclin D1 and aromatase was determined using RT-PCR. Gefitinib reduced GPER expression concentration- and time-dependently. In HCC70 cells, GPER expression was reduced to $15 \pm 11 \%(\mathrm{p}<0.05)$ after treatment with $200 \mathrm{nM}$ gefitinib for four days, and in HCC1806 cells GPER expression was reduced to $39 \pm 5 \%$ $(\mathrm{p}<0.01)$ of the control. $17 \beta$-estradiol significantly increased the percentage of $\mathrm{HCC} 1806$ cells within 7 days to $145 \pm 29 \%$ of the control (HCC70, 110 $\pm 8 \%$ ). This increase in cell growth was completely prevented in both TNBC cell lines after GPR30 expression was downregulated by treatment with $200 \mathrm{nM}$ gefitinib. In HCC1806 cells, activation of c-src was increased by $17 \beta$-estradiol to $350 \pm 50 \%(\mathrm{p}<0.01)$, and gefitinib reduced src activation to $110 \%$. Similar results were obtained in the HCC70 cells. Phosphorylation of EGFR increased to $240 \pm 40 \%$ $(\mathrm{p}<0.05)$ in the HCC1806 cells treated with $17 \beta$-estradiol (HCC70, 147 $\pm 25 \%$ ). Gefitinib completely prevented this activation. Phosphorylation of CREB and induction of c-fos, cyclin D1 and aromatase expression by $17 \beta$-estradiol were all
\end{abstract}

Correspondence to: Dr Rainer Girgert, Department of Gynecology and Obstetrics, School of Medicine, University of Göttingen, Robert Koch Street 40, D-37075 Göttingen, Germany

E-mail: rainer.girgert@med.uni-goettingen.de

Key words: triple-negative breast cancer, targeted therapy, GPER, EGFR, gefitinib, signal transduction prevented by gefitinib. These experiments conclusively show that reduction of GPER expression is a promising therapeutic approach for TNBC.

\section{Introduction}

Triple-negative breast cancer (TNBC) accounts for $10-15 \%$ of all breast cancer cases (1). These tumors can currently only be treated by conventional chemotherapy as they lack expression of estrogen receptor $\alpha(\mathrm{ER} \alpha)$ and progesterone receptors and cannot be treated with HER2 antibody trastuzumab or other HER2 directed therapies. To date, no successful targeted therapy is available for TNBC patients (2). Consequently, the mortality rate of TNBC patients is still twice as high as for patients having $E R \alpha$-positive tumors (3). A high proportion (30-52\%) of TNBCs overexpress epidermal growth factor receptor (EGFR) and this high expression of EGFR is associated with poor prognosis (4). A number of tyrosine kinase inhibitors (TKIs) preferentially acting on EGFR have been developed in the last decades. Gefitinib (Iressa ${ }^{\circledR}$ ) and erlotinib are compounds possessing a high affinity to the hydrophobic ATP-binding pocket of the tyrosine kinase domain of EGFR (5). Gefitinib (ZD1839 or Iressa ${ }^{\circledR}$ ) was found to inhibit proliferation of EGFR-overexpressing cancer cell lines by more than $50 \%$, including the TNBC cell line MDA-MB-231 (6).

In a phase II multicenter trial with advanced breast cancer patients, treatment with $500 \mathrm{mg}$ gefitinib per day achieved stable disease for 6 months in $38.7 \%$ of patients. Immunohistochemical staining of biopsies of treated patients demonstrated a complete inhibition of EGFR phosphorylation (7). Particularly, breast tumors that developed resistance to tamoxifen benefited from gefitinib treatment showing stable disease for 24 weeks in $54 \%$ of patients. In the same study, only $11.5 \%$ of ER-negative patients showed stable disease under gefitinib treatment (8).

GPER, also known as GPR30, is a G protein-coupled receptor responsible for nongenomic actions of $17 \beta$-estradiol $(9,10)$. Binding of $17 \beta$-estradiol to GPER leads to a dissociation of the heterotrimeric G-protein complex. The $\beta \gamma$-subunit activates the tyrosine kinase Src (11). Subsequently, matrix metalloproteases release EGF from the extracellular matrix that initiates autophosphorylation of the EGFR finally leading to the activation of the ras-MAP-kinase pathway (9). 
In addition, it has been shown that stimulation of GPER by the synthetic agonist G1 suppressed EMT in the TNBC cell line MDA-MB-231 by downregulation of NF- $\kappa \mathrm{B}$ signaling (12). High GPER expression in the breast is one reason for acquired tamoxifen resistance of breast tumors as tamoxifen has been shown to be an agonist of GPER (13).

In TNBC, GPER is also frequently expressed very strongly and high GPER expression in this subgroup of breast cancer was found to correlate with increased recurrence (14). Recently, we provided evidence, that inhibition of the transcription of GPR30 by siRNA is able to prevent $17 \beta$-estradiol-dependent growth stimulation of TNBC (15). As siRNA is not applicable in patients, other approaches to lower GPER are necessary. Vivacqua et al reported that in breast cancer cells high expression of GPER correlates with overexpression of the EGFR (16). On the other hand, EGFR is overexpressed in approximately $50 \%$ of TNBCs and high EGFR expression is a predictor of a poor prognosis of these breast cancer patients (17).

In the present study, we therefore analyzed the impact of gefitinib on GPER expression and on 17 $\beta$-estradiol-dependent growth stimulation in TNBC cells.

\section{Materials and methods}

Reagents. Gefitinib (Iressa ${ }^{\circledR}$ ) was purchased from Selleck Chemicals (Houston, TX, USA). 17 $\beta$-estradiol (E2), insulin and transferrin were purchased from Sigma-Aldrich (Deisendorf, Germany).

Cell lines. TNBC cell lines HCC70 and HCC1806 both of the basal-like subtype were purchased from the American Type Culture Collection (ATCC; Manassas, VA, USA) and maintained in Dulbecco's modified Eagle's medium (DMEM) (Biochrom GmbH, Berlin, Germany) supplemented with $2 \mathrm{mM}$ glutamine, $6 \mathrm{ng} / \mathrm{ml}$ insulin, $10 \mathrm{ng} / \mathrm{ml}$ transferrin, penicillin $(50 \mathrm{U} / \mathrm{ml})$, streptomycin $(50 \mu \mathrm{g} / \mathrm{ml})$ from Gibco (Paisley, $\mathrm{UK}$ ) and $10 \%$ fetal bovine serum (Biochrom $\mathrm{GmbH}$ ).

Proliferation assays. Proliferation assays were performed as previously described (18). Charcoal depleted serum (CD-FCS) was prepared according to the procedure described by Stanley et al (19). Cell number was determined by a colorimetric method using Alamar Blue (Biosource, Solingen, Germany).

Proliferation assays were performed at least three times in quadruplicates with different passages. Means and standard deviations of the optical density (OD) of the replicates were calculated.

Treatment of cells. Four million cells of either cell line (HCC70 and HCC1806) were treated for $48 \mathrm{~h}$ with $200 \mathrm{nM}$ gefitinib. Twenty-four hours before harvest, the cells were starved from serum. Finally, the cells were stimulated for $15 \mathrm{~min}$ with $10^{-8} \mathrm{M}$ $17 \beta$-estradiol. Cells were detached with $1 \mathrm{mM}$ EDTA/PBS and the pellets were lysed in $50 \mu \mathrm{l}$ CelLytic M containing protease and phosphatase inhibitors (Sigma-Aldrich).

Western blotting. Lysates of cells were cleared and protein was determined using the method of Bradford. Twenty

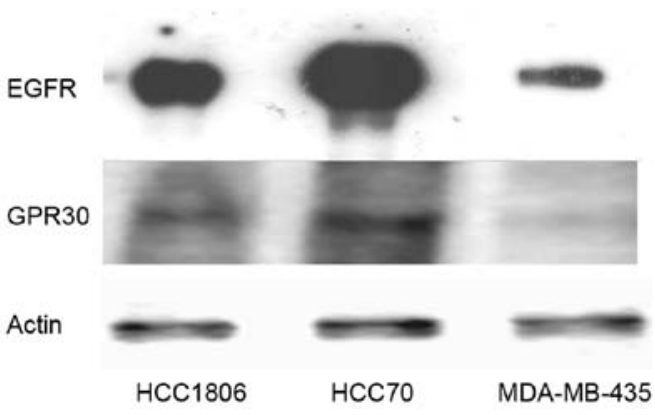

Figure 1. Expression of epidermal growth factor receptor (EGFR) and GPR30 in triple-negative breast cancer cell lines. Twenty micrograms of protein from the HCC1806, HCC70 and MDA-MB-435 cells were analyzed by western blotting for expression of EGFR and GPR30. Non-amplified MDA-MB-435 cells expressed the lowest amount of EGFR. HCC70 cells expressed the highest amount of EGFR (upper panel). In parallel, GPR30 expression was lowest in the MDA-MB-435 cells and highest in the HCC70 cells. Detection of $\beta$-actin confirmed that equal amounts of protein were blotted in the western blotting. Representative results of three independent preparations

micrograms of each sample were separated in a $7.5 \%$ polyacrylamide gel, blotted on a PVDF membrane and detected with rabbit anti-human primary antibodies: anti-GPR30 (sc-48524; Santa Cruz Biotechnology, Inc., Dallas, TX, USA), anti-phospho-Src (2113) and anti-Src (2109) from Cell Signaling Technology, Inc. (Danvers, MA, USA), anti-phospho-Tyr ${ }^{1173}$ EGFR (324864) from Calbiochem (Darmstadt, Germany), anti-EGFR antibody (2235) supplied by Epitomics (Hamburg, Germany) and anti-actin by Sigma-Aldrich. Blots were washed four times in TBST and further incubated with a 1:20,000 dilution of horseradish peroxidase conjugated goat anti-rabbit antibody (ECL; GE Healthcare, Freiburg, Germany). After washing again for four times, the blots were incubated with chemoluminescence reagent Femto (Thermo Fisher Scientific, Rockford, IL, USA) for 5 min and emitted light was detected on a LI-COR chemoluminescence detector (LI-COR Biosciences, Lincoln, NE, USA). Densitometric evaluation of the protein bands was performed with Image Studio Digits program from LI-COR and expression values of the proteins were normalized to actin.

$R T-P C R$. RNA of the variously treated TNBC cells was purified using the RNeasy kit (Qiagen, Hilden, Germany). Reverse transcription-polymerase chain reaction of c-fos, cyclin D1 and aromatase was performed as previously described (15).

Agarose gels of PCR products were stained in ethidium bromide $(2 \mu \mathrm{g} / \mathrm{ml})$ for $30 \mathrm{~min}$ and photographed on a transiluminator using a CDS camera (Biometra, Göttingen, Germany). The band intensities of the PCR products were evaluated by the Digital Science 1D software (Eastman Kodak, Rochester, NY, USA). Values of the RT-PCR products were normalized to the ribosomal protein $\mathrm{L} 7$.

Statistical analysis. The data were tested for significant differences by one-way analysis of variance followed by Student-Newman-Keuls test for comparison of individual groups, after a Bartlett's test had shown that variances were homogenous. 


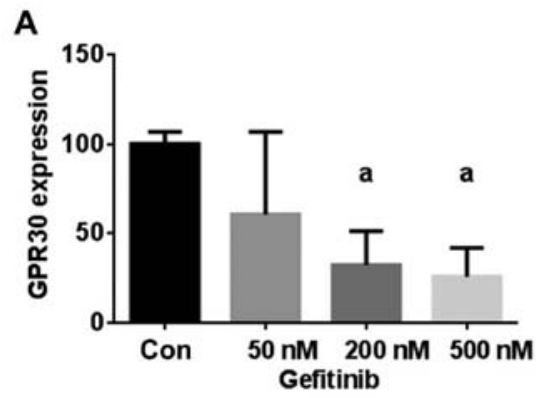

C

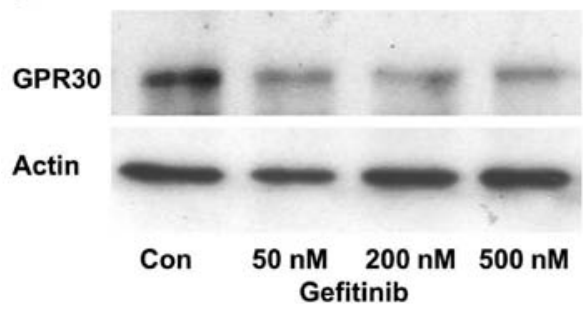

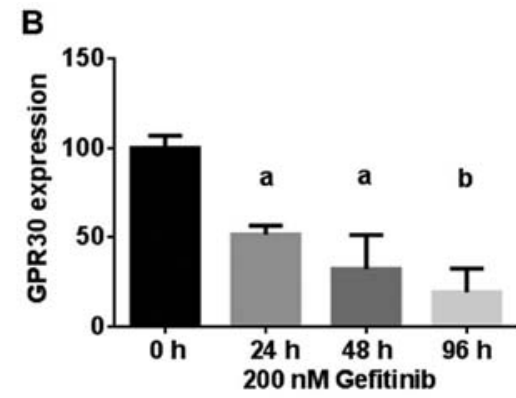

D

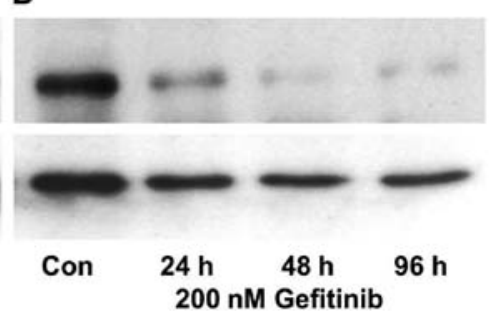

Figure 2. Reduction of GPER expression in HCC1806 cells after treatment with gefitinib. (A) Concentration dependence. HCC1806 cells were treated with 50-500 nM gefitinib for $48 \mathrm{~h}$. GPER was detected by western blotting. (B) Time dependence. HCC1806 cells were treated with $200 \mathrm{nM}$ gefitinib for $24-96 \mathrm{~h}$. ${ }^{a} \mathrm{p}<0.05$ vs. control; ${ }^{b} \mathrm{p}<0.001$ vs. control. Mean values and SE of three independent experiments are shown. (C) Representative western blotting of concentration dependence. (D) Representative western blotting of time dependence.

\section{Results}

Expression of EGFR and GPER in TNBC cell lines. In order to verify the assumption that expression of GPER parallels the expression of EGFR, $20 \mu \mathrm{g}$ protein of the TNBC cell lines HCC1806, HCC70 and MDA-MB-435 were analyzed on western blotting for expression of EGFR and GPER (Fig. 1). MDA-MB-435 cells, not amplified for the EGFR gene, contained the lowest amount of EGFR protein. HCC1806 cells expressed 15 \pm 3.2 -fold the amount of EGFR expressed in the MDA-MB-435 cells. The signal of EGFR was strongest in the HCC70 cells, expressing 48 \pm 5.8 -fold more EGFR than that noted in the MDA-MB- 435 cells.

The analysis of GPER expression in TNBC cell lines confirmed the observation of Vivacqua et al that GPER expression correlates with the amount of EGFR pointing to a direct regulation of GPER by EGF (16). In the cell lines tested, GPER expression was lowest in the MDA-MB-435 cells similar to EGFR and GPER expression was higher in cell lines expressing more EGFR. In the HCC1806 cells, GPER expression was 3.8 \pm 0.9 -fold the amount detected in the MDA-MB-435 cells and HCC70 cells expressed 8.4 \pm 1.4 -fold as much GPER as cells of the cell line MDA-MB- 435 .

Reduction in GPER expression following treatment with gefitinib. To test the hypothesis that inhibition of EGFR reduces expression of GPER, the TNBC cell lines were treated with increasing concentrations of gefitinib for up to 4 days and GPER expression was analyzed by western blotting of the lysates of the treated cells (Fig. 2). A 2-day treatment of HCC 1806 cells with $50 \mathrm{nM}$ gefitinib reduced GPER expression to $60.5 \pm 46 \%$ of the control (NS). Using $200 \mathrm{nM}$ gefitinib, GPER expression was reduced to $32 \pm 18 \%(\mathrm{p}<0.05)$ and $500 \mathrm{nM}$ gefitinib lowered GPER expression in the HCC1806 cells further to $26 \pm 16 \%$ (p<0.05) (Fig. 2A). The inhibition of
GPER expression was also found to be more effective with increasing time of exposure to gefitinib. In the HCC1806 cells treated with $200 \mathrm{nM}$ gefitinib for $24 \mathrm{~h}$, GPER expression decreased to $52 \pm 5 \%(\mathrm{p}<0.05)$ and after $96 \mathrm{~h}$ the GPER level reached $39 \pm 5 \%(\mathrm{p}<0.01)$ of the control (Fig. 2B). Fig. 2C shows a representative western blot of the concentrationdependent reduction in GPER expression by gefitinib in the HCC1806 cells. Similar results were obtained with the TNBC cell line HCC70. In Fig. 2D, a representative western blot of the time-dependent decrease in GPER expression after treatment with $200 \mathrm{nM}$ gefitinib for $24-96 \mathrm{~h}$ is presented.

Treatment of HCC70 cells with $200 \mathrm{nM}$ gefitinib led to an almost maximal reduction in GPER expression after $24 \mathrm{~h}$ to $25 \pm 7 \%(\mathrm{p}<0.01)$ of the control and GPER expression further decreased only slightly after a $96-\mathrm{h}$ treatment with $200 \mathrm{nM}$ gefitinib $(15 \pm 11 \%)(\mathrm{p}<0.01)$ (Table I).

Reduction of GPER expression by gefitinib prevents growth stimulation of TNBC by $17 \beta$-estradiol. As additional proof that the inhibitory effect of gefitinib on the growth of TNBC depends in part on a reduction in GPER expression, the effect of 17 $\beta$-estradiol on the proliferation of the TNBC cell lines was analyzed at a concentration of $10^{-8} \mathrm{M}$ in the absence or in the presence of $200 \mathrm{nM}$ gefitinib (Fig. 3). Within 7 days of culture, the percentage of HCC1806 cells increased to $145 \pm 29 \%(\mathrm{p}<0.01)$ in the presence of $17 \beta$-estradiol compared to the controls. Treatment of HCC1806 cells with $200 \mathrm{nM}$ gefitinib alone reduced the percentage of cells to $76 \pm 14 \%$ of the control. When HCC1806 cells treated with gefitinib were stimulated by $17 \beta$-estradiol, the percentage of cells only slightly increase to $85 \pm 28 \%$ and remained below the control level (Fig. 3, left). The induction of growth of HCC70 cells by $10^{-8} \mathrm{M} 17 \beta$-estradiol was less pronounced with an increase of $110 \pm 8 \%$ of the control; following treatment with $200 \mathrm{nM}$ gefitinib the percentage of HCC70 cells was $76 \pm 11 \%$ of the 
Table I. Quantitative evaluation of GPER expression after treatment of TNBC cells with various concentrations of gefitinib for 24 to $96 \mathrm{~h}$.

Treatment of HCC1806 cells

\begin{tabular}{llrr}
\cline { 2 - 4 } Concentrations & \multicolumn{1}{c}{$50 \mathrm{nM}$} & $200 \mathrm{nM}$ & $500 \mathrm{nM}$ \\
\hline Duration & & & \\
$24 \mathrm{~h}$ & $64 \pm 16 \%(\mathrm{p}<0.01)$ & $52 \pm 5 \%(\mathrm{p}<0.001)$ & $32 \pm 6 \%(\mathrm{p}<0.001)$ \\
$48 \mathrm{~h}$ & $60 \pm 46 \%(\mathrm{NS})$ & $32 \pm 18 \%(\mathrm{p}<0.05)$ & $26 \pm 16 \%(\mathrm{p}<0.05)$ \\
$96 \mathrm{~h}$ & $49 \pm 32 \%(\mathrm{p}<0.05)$ & $39 \pm 5 \%(\mathrm{p}<0.01)$ & $26 \pm 18 \%(\mathrm{p}<0.01)$ \\
\hline
\end{tabular}

Treatment of HCC70 cells

\begin{tabular}{lccc}
\cline { 2 - 4 } Concentrations & $50 \mathrm{nM}$ & $200 \mathrm{nM}$ & $500 \mathrm{nM}$ \\
\hline Duration & & & \\
$24 \mathrm{~h}$ & $28 \pm 8 \%(\mathrm{p}<0.001)$ & $25 \pm 7 \%(\mathrm{p}<0.001)$ & $25 \pm 10 \%(\mathrm{p}<0.001)$ \\
$48 \mathrm{~h}$ & $31 \pm 18 \%(\mathrm{p}<0.01)$ & $29 \pm 6 \%(\mathrm{p}<0.01)$ & $21 \pm 8 \%(\mathrm{p}<0.01)$ \\
$96 \mathrm{~h}$ & $35 \pm 19 \%(\mathrm{p}<0.01)$ & $15 \pm 11 \%(\mathrm{p}<0.01)$ & $28 \pm 19 \%(\mathrm{p}<0.01)$
\end{tabular}

NS, not significant.

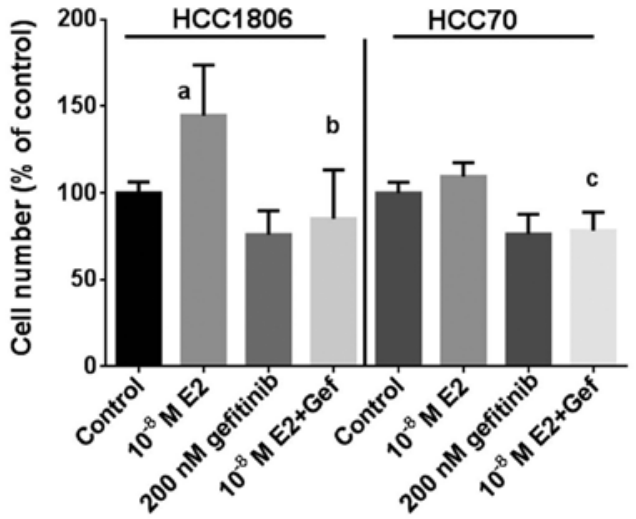

Figure 3. Inhibition of $17 \beta$-estradiol-induced cell proliferation by gefitinib in triple-negative breast cancer (TNBC) cell lines. HCC1806 (left) and HCC70 (right) cells were grown for 7 days in phenol red-free medium supplemented with charcoal-stripped serum (control) or in the presence of $10^{-8} \mathrm{M}$ $17 \beta$-estradiol (E2) or cotreated with $200 \mathrm{nM}$ gefitinib (Gef). Cell number was estimated with a colorimetric assay using Alamar Blue. Mean values and SE of three independent experiments with four replicates are shown. ${ }^{a} \mathrm{p}<0.001$ vs. control; ${ }^{\mathrm{b}} \mathrm{p}<0.001$ vs. $10^{-8} \mathrm{M} \mathrm{E} 2 ;{ }^{\mathrm{c}} \mathrm{p}<0.01$ vs. $10^{-8} \mathrm{M} \mathrm{E} 2$.

control. In the HCC70 cells co-treated with gefitinib stimulation with $17 \beta$-estradiol failed to increase the cell percentage after 7 days of culture ( $78 \pm 11 \%$ ) (Fig. 3, right).

Gefitinib inhibits GPER-dependent phosphorylation of c-src and subsequent activation of EGFR. Next, the impact of the reduction in GPER expression by gefitinib was analyzed on the indirect activation of $\mathrm{c}$-src and EGFR by $10^{-8} \mathrm{M} 17 \beta$-estradiol. The two TNBC cell lines, either pretreated with $200 \mathrm{nM}$ gefitinib for 4 days or not, were stimulated with $17 \beta$-estradiol and phosphorylation of c-src and EGFR was analyzed by western blotting (Fig. 4A and B).
Even in the serum-starved HCC1806 and HCC70 cells a basal phosphorylation of c-src at $\mathrm{Tyr}^{416}$ was detectable (lane 1).In both cell lines, phosphorylation of c-src was strongly increased after stimulation with $10^{-8} \mathrm{M} 17 \beta$-estradiol (Fig. 4A and B, lane 2). Densitometric analysis of the $\mathrm{p}$-src bands revealed that the amount of p-src was increased in the HCC1806 cells to $350 \pm 50 \%$ of the control ( $<<0.01$ ) (Fig. 4C) and in HCC70 cells to $220 \pm 30 \%(\mathrm{p}<0.05)$ (Fig. 4D). Pretreatment of the cells for $96 \mathrm{~h}$ with $200 \mathrm{nM}$ gefitinib did not change c-src phosphorylation (Fig. 4A and B, lane 3). In both TNBC cell lines pretreatment with $200 \mathrm{nM}$ gefitinib prevented activation of c-src by $10^{-8} \mathrm{M} 17 \beta$-estradiol. Whereas in the HCC1806 cells, phosphorylation of c-src by estradiol was diminished by gefitinib from 350 to $90 \%$ of the control (Fig. 4C). In the HCC70 cells, activation of c-src was reduced from 220 to $135 \%$ of the control, when pretreated for 4 days with $200 \mathrm{nM}$ gefitinib (Fig. 4D).

In the signal transduction of GPER, phosphorylated src activates matrix metalloproteases that release heparin-bound EGF from the extracellular matrix. After binding of EGF to its cognate receptor, EGFR is autophosphorylated at several sites of the cytosolic domain. The increased phosphorylation of the EGFR at $\mathrm{Tyr}^{1173}$ after stimulation of the HCC1806 and HCC70 cells with $10^{-8} \mathrm{M} 17 \beta$-estradiol is shown in Fig. 4A and B, lane 2 . In HCC1806 cells, Tyr ${ }^{1173}$ phosphorylation of EGFR increased to $240 \pm 40 \%(\mathrm{p}<0.01)$ of the non-stimulated control (Fig. 4C) and in HCC70 cells to $147 \pm 25 \%$ (Fig. 4D).

In both cell lines induction of $\mathrm{Tyr}^{1173}$ phosphorylation by $17 \beta$-estradiol was almost completely prevented in the cells pretreated with $200 \mathrm{nM}$ gefitinib: pEGFR in HCC1806, $120 \pm 10 \%$ of the control; in HCC70 cells, $80 \pm 10 \%$ of the control (Fig. 4C and D).

Pretreatment of TNBC with gefitinib reduces activation of $C R E$ by $17 \beta$-estradiol. In addition to the $\mathrm{G} \beta \gamma$-dependent activation 

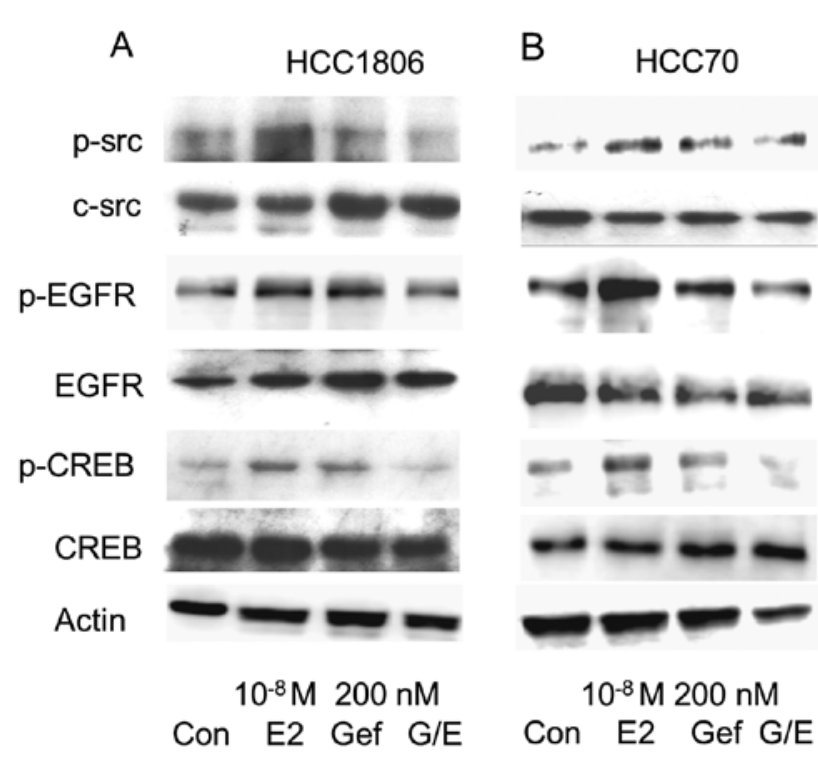

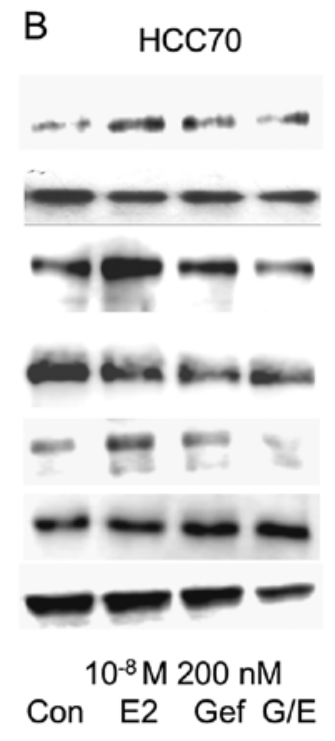

C

HCC1806
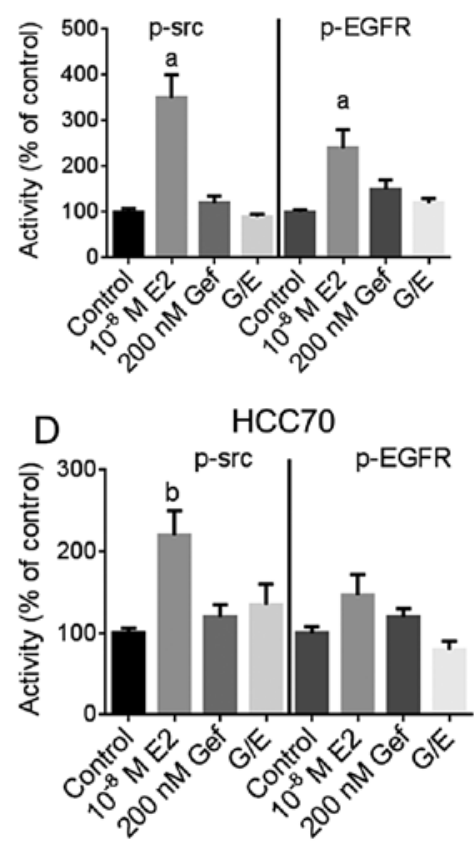

Figure 4. Inhibition of GPER-dependent signal transduction by pretreatment with gefitinib. Western blotting of (A) HCC1806 cells and (B) HCC70 cells. Serum-starved cells (control) were stimulated for $10 \mathrm{~min}$ with $10^{-8} \mathrm{M} 17 \beta$-estradiol (E2) (lane 2) or pretreated for $96 \mathrm{~h}$ with $200 \mathrm{nM}$ gefitinib (Gef) (lane 3 ) and gefitinib-treated cells were subsequently stimulated with $10^{-8} \mathrm{M} 17 \beta$-estradiol (G/E) for $10 \mathrm{~min}$ (lane 4). Cells were lysed, proteins were separated on a polyacrylamide gel, blotted onto a PVDF-membrane, and the indicated proteins were sequentially detected with antibodies against phospho (p)-src (panel 1), total-c-src (panel 2), p-EGFR (panel 3), total EGFR (panel 4), p-CREB (panel 5) or total CREB (panel 6). (C) Densitometry of p-src and pEGFR in HCC1806 cells. (D) Densitometry of p-src and pEGFR in HCC70 cells. ${ }^{a} \mathrm{p}<0.01 \mathrm{vs}$. control; ${ }^{b} \mathrm{p}<0.05 \mathrm{vs}$. control. Representative results of three independent preparations are presented.

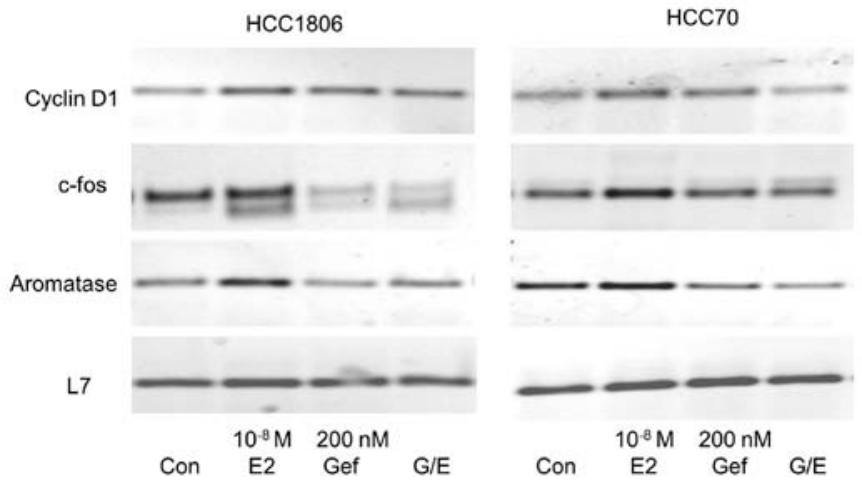

Figure 5. Influence of gefitinib on the induction of cyclin D1, c-fos and aromatase (CYP19A1) expression by $17 \beta$-estradiol in TNBC cell lines. HCC1806 (left) and HCC70 (right) cells were grown in serum-free medium for $24 \mathrm{~h}$ (Con) and subsequently stimulated with $10^{-8} \mathrm{M} 17 \beta$-estradiol for $30 \mathrm{~min}$ (E2). Cells were pretreated for $96 \mathrm{~h}$ with $200 \mathrm{nM}$ gefitinib and serum starved for $24 \mathrm{~h}(\mathrm{Gef})$ or subsequently stimulated with $17 \beta$-estradiol for $15 \mathrm{~min}(\mathrm{G} / \mathrm{E})$. RT-PCR for cyclin D1, c-fos and CYP19A1 was performed with mRNA isolated from the variously treated cells. RT-PCR for the ribosomal protein L7 proves equal RNA loading. Representative results of three independent preparations are shown.

of the GPER signaling pathway described above, stimulation of GPER by $17 \beta$-estradiol also results in the release of $\mathrm{G} \alpha$ from the heterotrimeric G-protein complex that activates adenylyl cyclase. As a consequence, activity of protein kinase A (PKA) is increased by cAMP leading to the phosphorylation of the cAMP-responsive element binding (CREB) protein.
Phosphorylation of CREB was analyzed by western blotting from cell lysates from the TNBC cell lines (Fig. 4, panels 5 and 6). Stimulation of HCC1806 cells with $10^{-8} \mathrm{M}$ $17 \beta$-estradiol increased phosphorylation of CREB to $144 \pm 8 \%$ (lane 2) compared to non-stimulated control cells (lane 1). In HCC 70 cells, CREB phosphorylation increased to $169 \pm 60 \%$ of the control due to stimulation with $17 \beta$-estradiol. When EGFR was inhibited by $200 \mathrm{nM}$ gefitinib prior to stimulation of HCC1806 and HCC70 cells with $10^{-8} \mathrm{M} 17 \beta$-estradiol, activation of CREB was completely prevented: pCREB in HCC1806 cells, $95 \pm 21 \%$; HCC70 cells, $82 \pm 17 \%$ (Fig. 4, lane 4).

Previously, we showed by electrophoretic mobility shift that after stimulation of TNBC cell lines HCC1806 and HCC70 with $17 \beta$-estradiol, phospho-CREB binds to the promoter of cyclin D1 (15).

Induction of cyclin D1 expression by $17 \beta$-estradiol is inhibited by gefitinib. Cyclin D1 is an important regulator of the transition from G1 to $\mathrm{S}$ phase of the cell cycle necessary for the induction of proliferation. Expression of cyclin D1 was analyzed after stimulation of both TNBC cell lines with $10^{-8} \mathrm{M}$ 17ß-estradiol for $30 \mathrm{~min}$ (Fig. 5, first panel).

In $\mathrm{HCC} 1806$ cells we observed a distinct expression of cyclin D1 mRNA in the serum-starved control cells. This high basal cyclin D1 expression increased to $125 \pm 16 \%$ after a 30-min stimulation with $10^{-8} \mathrm{M} 17 \beta$-estradiol (lane 2). In HCC1806 cells pretreated for $96 \mathrm{~h}$ with $200 \mathrm{nM}$ gefitinib, cyclin D1 expression was lower than in the control cells (lane 3). In the gefintinib-treated HCC1806 cells stimulation 
with $17 \beta$-estradiol was not able to increase cyclin D1 expression $(96 \pm 12 \%)$.

In the non-stimulated HCC70 cells, cyclin D1 was more strongly expressed than in the HCC1806 cells. A 30-min stimulation of these cells with $10^{-8} \mathrm{M} 17 \beta$-estradiol elevated the cyclin D1 mRNA content to $129 \pm 13 \%$ of the control (Fig. 5, lane 2). Pretreatment of HCC70 cells with $200 \mathrm{nM}$ gefitinib completely prevented induction of cyclin D1 expression by

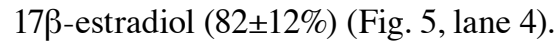

Gefitinib prevents induction of c-fos expression by $17 \beta$-estradiol. Following activation of EGFR, the growth promoting signal is forwarded via MAP kinase Erk to the nucleus where subsequent expression of $\mathrm{c}$-fos is induced. Serum-starved cells of the two different TNBC cell lines (HCC1806 and HCC70) were stimulated for $30 \mathrm{~min}$ with $10^{-8}$ M $17 \beta$-estradiol. mRNA of these cells was analyzed for c-fos expression by RT-PCR and compared to the expression in non-stimulated cells. Stimulation of HCC1806 cells with $17 \beta$-estradiol increased c-fos expression to $155 \pm 35 \%(\mathrm{p}<0.05)$ of the control (Fig. 5, second panel, lane 2). In the HCC70 cells, induction of c-fos by estradiol was less pronounced reaching only $140 \pm 10 \%$ compared to the serum-starved control. In HCC1806 cells, wherein expression of GPER was reduced after treatment with $200 \mathrm{nM}$ gefitinib for $96 \mathrm{~h}$, c-fos expression was $45 \%$ lower than that in the control cells (Fig. 5, lane 3 ) and induction of c-fos expression by $17 \beta$-estradiol was completely prevented (48 $\pm 9 \%$ ) (Fig. 5, lane 4). In HCC70 cells pretreated with gefitinib a slight increase in c-fos expression was still observed but only by the factor $1.1 \pm 0.2$.

Aromatase expression in TNBC cells. Aromatase (CYP19A1) is an enzyme of the cytochrome 450 family catalyzing the formation of the non-saturated A-ring of estradiol. The promoter of the aromatase gene contains a cAMP-responsive element (20). For this reason we expected that aromatase is regulated by GPER. Stimulation of TNBC cell line HCC1806 cells with $17 \beta$-estradiol led to an increase in mRNA for aromatase to $128 \pm 25 \%$ (Fig. 5, third panel, lane 2). The reduction in GPER expression by pretreatment of HCC1806 cells with $200 \mathrm{nM}$ gefitinib for $96 \mathrm{~h}$ prevented the induction of aroma-

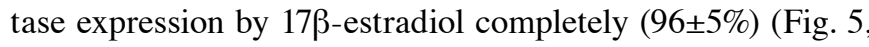
lane 4). In HCC70 cells $17 \beta$-estradiol increased aromatase expression to $137 \pm 10 \%$ but in cells pretreated with gefitinib mRNA of aromatase was less abundant than that in the control cells $(65 \pm 18 \%)$.

\section{Discussion}

Patients with TNBC have very poor prognosis due to the lack of expression of $\mathrm{ER} \alpha$, progesterone receptor and HER2-amplification in their tumors. EGFR is overexpressed in about $50 \%$ of TNBC and high EGFR expression predicts the poor prognosis of these breast cancer patients (17).

Although TNBC cells per definition do not express the nuclear estrogen receptor $\mathrm{ER} \alpha$, we observed a growth stimulation of $45 \%$ in the TNBC cell line HCC1806 by $17 \beta$-estradiol (Fig. 3). This enhanced growth is caused by GPER, the estrogen receptor responsible for the non-genomic effects of $17 \beta$-estradiol. Previously, we showed that knockdown of GPER using specific siRNA prevented this growth stimulation by $17 \beta$-estradiol in TNBC cell lines (15). In search of more physiological ways to downregulate GPER expression, we found in the literature the indication that GPER expression parallels the expression of EGFR (16). In TNBC, strong expression of GPER is also prevalent in addition to overexpression of EGFR and strong GPER expression in this cohort was associated with young age and poor outcome (14).

There are small molecular compounds, such as gefitinib or erlotinib, binding to the kinase domain of the EGFR and successfully inhibiting phosphorylation of the cytosolic domain of EGFR and downregulating EGFR signaling (5).

Here, we proved the interrelation between GPER expression and EGFR activity, as inhibition of EGFR using gefitinib dramatically reduced GPER expression for example by up to $85 \%$ in the HCC70 cells after $96 \mathrm{~h}$ (Table I).

In fact, this downregulation of GPER expression by gefitinib reduced the induction of cell growth of HCC1806 and HCC70 cells by $10^{-8} \mathrm{M} 17 \beta$-estradiol below the level of non-stimulated cells $(85 \pm 28$ and $76 \pm 11 \%$, respectively).

Clinical trials treating an unselected population of breast cancer patients with gefitinib as a single agent were not successful. Nonetheless, immunohistochemical analysis of biopsies of treated tumors revealed complete inhibition of EGFR phosphorylation (7). In a further study, the treatment of 58 heavily pretreated patients with metastatic breast cancer using $500 \mathrm{mg}$ gefitinib per day resulted in partial tumor response in one patient (21).

In one clinical trial particularly targeting EGFR in TNBC patients with gefitinib, stable disease for 24 weeks was achieved at least in two of 25 patients (22). There are probably alternative mechanisms of pathway activation circumventing EGFR activation (23).

In a phase II trial of 181 women with ER-negative breast cancer, pathologic complete response (pCR) to gefitinib was achieved in $17 \%$ of TNBC patients, whereas in only $2 \%$ of non-TNBC patients pCR was observed after gefitinib treatment for 12 weeks (24).

In the present study, we investigated a new strategy to target GPER in TNBC. We used $200 \mathrm{nM}$ gefitinib (Iressa ${ }^{\circledR}$ ) as a selective reversible inhibitor of EGFR tyrosine kinase to downregulate GPER expression. Clinical trials for breast cancer have been performed with a daily dosage of $500 \mathrm{mg}$ gefitinib resulting in an estimated serum concentration of approximately $100 \mu \mathrm{M}(7)$.

In order to confirm the specificity of the downregulation of GPER expression by gefitinib, we analyzed the downstream signaling of GPER after downregulation of its expression by gefitinib. As described by Filardo et al the tyrosine kinase Src is activated by the $\beta \gamma$-subunit of heterotrimeric G-proteins after binding of $17 \beta$-estradiol to GPER and EGF released from the extracellular matrix by matrix metalloproteases induces autophosphorylation of the EGFR (9).

As shown in Fig. 4, downregulation of GPER expression completely prevented activation of the non-receptor tyrosine kinase c-src and of EGFR activation by $17 \beta$-estradiol. Attempts to pharmacologically inhibit GPER in TNBC cell lines using estriol or the GPER-specific inhibitor G15 also proved promising but the concentrations of these inhibitors necessary to achieve a sufficient reduction of $17 \beta$-estradiol-induced cell 
proliferation were not achievable in vivo (25). This fact rules out an application of these compounds in clinical trials.

In this study, we showed that the proportion of growth of TNBC cells that was induced by $17 \beta$-estradiol was successfully inhibited by gefitinib via reduction of GPER expression. The use of gefitinib may be a therapeutic option particularly in TNBCs expressing high amounts of GPER. We expect from our results that in TNBC patients selected for high expression of GPER, gefitinib will prove to be more effective than in an unselected population of breast cancer patients.

\section{Acknowledgements}

We thank Sonja Blume for the excellent technical assistance. This study was supported by grant GR $1895 / 10-1$ of the German Research Foundation.

\section{References}

1. Petrelli F, Cabiddu M, Ghilardi M and Barni S: Current data of targeted therapies for the treatment of triple-negative advanced breast cancer: Empiricism or evidence-based? Expert Opin Investig Drugs 18: 1467-1477, 2009.

2. Podo F, Buydens LM, Degani H, Hilhorst R, Klipp E, Gribbestad IS, Van Huffel S, van Laarhoven HW, Luts J, Monleon D, et al; FEMME Consortium: Triple-negative breast cancer: Present challenges and new perspectives. Mol Oncol 4: 209-229, 2010.

3. Carey LA, Dees EC, Sawyer L, Gatti L, Moore DT, Collichio F, Ollila DW, Sartor CI, Graham ML and Perou CM: The triple negative paradox: Primary tumor chemosensitivity of breast cancer subtypes. Clin Cancer Res 13: 2329-2334, 2007.

4. Reis-Filho JS and Tutt AN: Triple negative tumours: A critical review. Histopathology 52: 108-118, 2008.

5. Wakeling AE, Guy SP, Woodburn JR, Ashton SE, Curry BJ, Barker AJ and Gibson KH: ZD1839 (Iressa): An orally active inhibitor of epidermal growth factor signaling with potential for cancer therapy. Cancer Res 62: 5749-5754, 2002.

6. Anderson NG, Ahmad T, Chan K, Dobson R and Bundred NJ: ZD1839 (Iressa), a novel epidermal growth factor receptor (EGFR) tyrosine kinase inhibitor, potently inhibits the growth of EGFR-positive cancer cell lines with or without erbB2 overexpression. Int J Cancer 94: 774-782, 2001.

7. Baselga J, Albanell J, Ruiz A, Lluch A, Gascón P, Guillém V, González S, Sauleda S, Marimón I, Tabernero JM, et al: Phase II and tumor pharmacodynamic study of gefitinib in patients with advanced breast cancer. J Clin Oncol 23: 5323-5333, 2005.

8. Gutteridge E, Agrawal A, Nicholson R, Leung Cheung K, Robertson $\mathrm{J}$ and Gee $\mathrm{J}$ : The effects of gefitinib in tamoxifen-resistant and hormone-insensitive breast cancer: A phase II study. Int J Cancer 126: 1806-1816, 2010.

9. Filardo EJ, Quinn JA, Frackelton AR Jr and Bland KI: Estrogen action via the $G$ protein-coupled receptor, GPR30: Stimulation of adenylyl cyclase and cAMP-mediated attenuation of the epidermal growth factor receptor-to-MAPK signaling axis. Mol Endocrinol 16: 70-84, 2002.

10. Haynes MP, Li L, Sinha D, Russell KS, Hisamoto K, Baron R, Collinge M, Sessa WC and Bender JR: Src kinase mediates phosphatidylinositol 3-kinase/Akt-dependent rapid endothelial nitric-oxide synthase activation by estrogen. J Biol Chem 278: 2118-2123, 2003.
11. Luttrell LM, Daaka Y and Lefkowitz RJ: Regulation of tyrosine kinase cascades by G-protein-coupled receptors. Curr Opin Cell Biol 11: 177-183, 1999.

12. Chen ZJ, Wei W, Jiang GM, Liu H, Wei WD, Yang X, Wu YM, Liu H, Wong CK, Du J, et al: Activation of GPER suppresses epithelial mesenchymal transition of triple negative breast cancer cells via NF- $\kappa$ B signals. Mol Oncol 10: 775-788, 2016.

13. Ignatov A, Ignatov $\mathrm{T}$, Weissenborn $\mathrm{C}$, Eggemann $\mathrm{H}$, Bischoff J, Semczuk A, Roessner A, Costa SD and Kalinski T: G-protein-coupled estrogen receptor GPR30 and tamoxifen resistance in breast cancer. Breast Cancer Res Treat 128: 457-466, 2011.

14. Steiman J, Peralta EA, Louis S and Kamel O: Biology of the estrogen receptor, GPR30, in triple negative breast cancer. Am J Surg 206: 698-703, 2013.

15. Girgert R, Emons G and Gründker C: Inactivation of GPR30 reduces growth of triple-negative breast cancer cells: Possible application in targeted therapy. Breast Cancer Res Treat 134: 199-205, 2012.

16. Vivacqua A, Lappano R, De Marco P, Sisci D, Aquila S, De Amicis F, Fuqua SA, Andò $S$ and Maggiolini M: G protein-coupled receptor 30 expression is up-regulated by EGF and TGF alpha in estrogen receptor alpha-positive cancer cells. Mol Endocrinol 23: 1815-1826, 2009.

17. Nielsen TO, Hsu FD, Jensen K, Cheang M, Karaca G, Hu Z, Hernandez-Boussard T, Livasy C, Cowan D, Dressler L, et al: Immunohistochemical and clinical characterization of the basal-like subtype of invasive breast carcinoma. Clin Cancer Res 10: 5367-5374, 2004.

18. Girgert R, Bartsch C, Hill SM, Kreienberg R and Hanf V: Tracking the elusive antiestrogenic effect of melatonin: A new methodological approach. Neuro Endocrinol Lett 24: 440-444, 2003.

19. Stanley ER, Palmer RE and Sohn U: Development of methods for the quantitative in vitro analysis of androgen-dependent and autonomous Shionogi carcinoma 115 cells. Cell 10: 35-44, 1977.

20. Chen S, Zhou D, Yang C, Okubo T, Kinoshita Y, Yu B, Kao YC and Itoh T: Modulation of aromatase expression in human breast tissue. J Steroid Biochem Mol Biol 79: 35-40, 2001.

21. von Minckwitz G, Jonat W, Fasching P, du Bois A, Kleeberg U, Lück HJ, Kettner E, Hilfrich J, Eiermann W, Torode J, et al: A multicentre phase II study on gefitinib in taxane- and anthracycline-pretreated metastatic breast cancer. Breast Cancer Res Treat 89: 165-172, 2005.

22. Green MD, Francis PA, Gebski V, Harvey V, Karapetis C, Chan A, Snyder R, Fong A, Basser R and Forbes JF; Australian New Zealand Breast Cancer Trials Group: Gefitinib treatment in hormone-resistant and hormone receptor-negative advanced breast cancer. Ann Oncol 20: 1813-1817, 2009.

23. Carey LA, Rugo HS, Marcom PK, Mayer EL, Esteva FJ, Ma CX, Liu MC, Storniolo AM, Rimawi MF, Forero-Torres A, et al: TBCRC 001: Randomized phase II study of cetuximab in combination with carboplatin in stage IV triple-negative breast cancer. J Clin Oncol 30: 2615-2623, 2012.

24. Bernsdorf M, Ingvar C, Jörgensen L, Tuxen MK, Jakobsen EH, Saetersdal A, Kimper-Karl ML, Kroman N, Balslev E and Ejlertsen B: Effect of adding gefitinib to neoadjuvant chemotherapy in estrogen receptor negative early breast cancer in a randomized phase II trial. Breast Cancer Res Treat 126: 463-470, 2011.

25. Girgert R, Emons G and Gründker C: Inhibition of GPR30 by estriol prevents growth stimulation of triple-negative breast cancer cells by 17 $\beta$-estradiol. BMC Cancer 14: 935, 2014. 